\title{
La respuesta frente a la delincuencia en el Estado de Derecho: lineamientos de un proceso penal democrático latinoamericano'
}

I.

"Ya no se necesita un acusador; ésta es la modificación más nolable. Aparece el principio oficial en forma inquisitori... El proceso pierde, poco a poco, las cualidades de oralidad y publicidad... en lo relativo a la prueba, entra, del derecho germano, el juramento de purificación del demandado; la tortura se aplica ampliamente. Poco a poco se constituye una teoría formal de la prueba que prescribe al juez bajo qué presupuestos formales tiene que creer o no cree un hecho". Con estas palabras describía el jurista alemán Emst Beling ${ }^{2}$ cl proceso de recepción del derecho romano canónico en el territorio alemán, y la transformación radical que ella produjo en el procedimiento penal romano-germánico (romántico), transformación que culmina con la consagración definitiva del sistema inquisitivo, reflejado emblemáticamente en la "Constitutio Criminalis Carolina" de 1532.

Alemania tarda más de trescientos años en abandonar definitivamente el sistema inquisitivo: recién a mediados del siglo XIX se comienza a extender a lo largo de los estados locales que la componen un intenso reformista, que culmina en la sanción de la Ordenanza Procesal Penal del Reich en 1877, la cuál, siguiendo precisamente las bases de las legislaciones que se habían diclado los estados, adopta, para no abandonarlo más, un sistema de enjuiciamiento caracterizado por la abolición del inquisidor, colocando en su lugar al ministerio público, del proceso escrito, mediato y secreto, reemplazado por el debate oral, público y contradictorio, y del sistema de prueba legal o tasada, sustituido ahora por el de libre apreciación de la prueba. El imputado abandona su único y penoso rol de objeto de prueba y del procedimiento para ser incorporado como sujeto procesal, con derechos plenos de intervención y control?" 
He elegido a la hoy República Federal de Alemania como ejemplo casi arbitrariamente, pero el proceso histórico descriplo es prácticamente uniforme en toda Europa continental: la irrupción cultural del lluminismo en las postrimerías del s. XVIII, su denuncia de la barbarie y del despotismo inquisitivo y su reivindicación de la tradición acusatoria4, conducen a un intento fallido de reimplantar un sistema acusatorio "puro" (la ley de enjuiciamiento francesa postrevolucionaria de 1971), primero, y luego, al movimiento de codificación europeo sobre la base del Code d'instruction criminelle de 1808 . El resultado de este proceso es la consolidación en Europa continental del sistema de enjuiciamiento penal llamado "mixto", por algunos, o "inquisitivo reformado", por otros, según donde se desee acentuar el análisis: es decir, un modelo con una marcada tendencia inquisitiva en la etapa de investigación preliminar al juicio, y, en cambio, un claro predominio del principio acusatorio durante la etapa del debate, este sí, contradictorio, oral y público.

El modelo "mixto" no logra, sin embargo, perdurar inalterado por demasiado tiempo. El s. XX, si bien no presenta una revolución cultural comparable a la transformación procesal provocada por el ideario humanista y libertario de la llustración, contiene, en lo mucho que va de él, una serie de modificaciones sustanciales que han ido tallando los rasgos distintivos del procedimiento penal europeo de fin de siglo. Por lo pronto, ya la experiencia práctica había dejado al desnudo que la misma estructura del sistema "mixto" en su versión clásica, con su etapa de instrucción burocrática y formalizada, secreta, escrita, y habitualmente colocada en manos de un juez, conducía a un completo bastardeo de la idea ilustrada de un juicio público impregnado de elementos acusatorios; muy por el contrario, el juicio, de hecho, se reducía, en palabras de Ferrajoli, a una "mera repetición o escenificación de la primera fase"s.

El "juicio oral" del ideario iluminista poco tenía que ver con el "juicio leído" al que había conducido la solución de compromiso entre acusación e inquisición de los sistemas mixlos. Al mismo liempo, esta estructura minaba la capacidad del sistema penal de responder con un mínimo de eficiencia frente a formas de delincuencia mucho más complejas que las conocidas por los pensadores del $\mathrm{s}$. XIX: se respondía - y en algunos casos, lodavía se responde- a estafas millonarias realizadas mediante complejísimas operaciones financieras con un juez de instrucción atiborrado de papeles y aclas, obligado, por regla, a investigar todos los hechos sometidos a su conocimiento y obligado también a realizar esta tarea controlando, simultáneamente, el respeto a las garanlías del sometido a proceso durante la investigación.

Frente a la dimensión y a la gravedad de estas críticas, era claro que los días del sistema mixto estaban contados: la consecuencia más importante de este diagnóstico fue la desaparición de la instrucción formalizada, escrita y burocrática, y, con ello, del juez de instrucción, y su reemplazo por una elapa de investigación preliminar ágil, formalizada sólo en lo atinente al resguardo de las garantías del imputado, 
y colocada en cabeza del detenedor de la acción penal: el ministerio público (asl, los CPP de Portugal (1988); la Ordenanza Procesal Penal alemana ya había suprimido la instrucción formal en la, así llamada, gran reforma procesal de 1974-750. El juez de instrucción queda exclusivamente a cargo del control de la legalidad del procedimiento, en general, y del resguardo de las garantías del impulado durante la etapa de investigación.

Por otro lado, la consagración internacional de los derechos humanos, concebidos como principios universales de cumplimiento obligatorio para los estados nacionales, positivizados en distintos instrumentos intemacionales, y la creación de jurisdicciones supranacionales encargadas de asegurar mediante su intervención el respeto a los derechos humanos, y prevenir su vulneración por parte de los Estados, tuvo importantísimas consecuencias para el procedimiento penal modemo.

Así, por ejemplo, ha sido este desarrollo el que ha conducido a la solución hoy uniforme- de que el principio de imparcialidad del juzgador (CADH, 8, 1 ; CEDH, 6; PIDCP, 14, 1) no sólo es violado medianle la grosera acumulación de las funciones de acusar y de decidir, característica del sistema inquisitivo, sino también de modos, en comparación, mucho más suliles, ni siquiera tenidos en cuenta por los diseñadores del sistema mixto: así, también se lesiona el principio de imparcialidad cuando el juez que integra el tribunal que va a decidir el caso, ha tenido intervención en etapas anteriores del procedimiento. El temor de parcialidad que ello produce, no permite afirmar que en un caso semejante, la garantía internacionalmente reconocida haya sido respetada ${ }^{\text {h }}$.

Lo dicho también vale para la evolución que ha experimentado la garantía de defensa en juicio, o para la reformulación de la utilización del encarcelamiento preventivo o provisional, reducido ahora a un supuesto de excepción en el marco de un modelo procesal que parte de la premisa de que el imputado debe permanecer, por regla, libre durante el trámite del procedimiento, debido al imperio de la presunción de inocencia.

Pero, a su vez, también la crítica extrasistemática al sistema penal ha jugado un rol determinante en la transformación del procedimiento penal experimentada durante este siglo. Los aportes de la criminología crítica, e, incluso, de las posiciones abolicionistas, han herido de muerte la idea de que el sistema penal, y, más aún, la pena estatal, constituyen un bien en si mismo. Muy por el contrario, hoy se sabe con certeza que el sistema penal es selectivo y concentra su actividad en las franjas de criminalidad baja y media, y en aquellos sectores más vulnerables de la población, y se sabe también que la pena de encierro carcelario - aún la que se presta en condiciones carcelarias respetuosas de la dignidad humana - no sólo no resocializa, sino que, por el contrario, conduce en la gran mayoría de los casos a la definitiva desocialización.

De esta nueva concepción del sistema penal surgen, por un lado, la adopción de mecanismos que buscan ordenar y racionalizar su selectividad intrínseca sobre la 
base de criterios legislativamente fijados, y que tienen como objetivo principal reforzar su capacidad operativa para la persecución de delitos que causen un serio daño soclal (principios de oportunidad), y, por el otro, a la búsqueda de soluciones altemativas a la penal estatal, incluso, ya durante el procedimiento, y de una incorporación de la víctima como protagonista real en la solución del conflicto social subyacente al delito: así, son desarrollos de este siglo la adopción de penas alternativas al encierro carcelario, la suspensión del procedimiento a prueba, o la idea de reparación como tercera vía del derecho penal'.

Resumiendo: el proceso de transformaciones que opera durante este siglo, próximo a su fin, en el ámbilo del procedimiento penal se caracteriza por tres lineamienlos fundamentales:

a) una profunda reforma del sistema mixlo, esto es, instrucción formal inquisitiva y debate con vocación acusaloria, mediante la desformalización y desburocratización de la elapa de investigación preliminar, ahora concebida como fase de preparación de la acción en manos del ministerio público, el cual, a su vez, es controlado por el juez de instruccion, custodio de las garantías de la persona sometida a proceso. Simultáneamente, se rejerarquiza de este modo el juicio oral, asegurando que sólo aquello que efectivamente ha acontecido en dicho ámbito - la prueba en él producida, controlada y criticada por las partes, y la contienda argumenlativa entre ellas pueda constituir la base para la decisión del caso;

b) el desarrollo de reglas que aseguren el pleno respelo durante el trámite del procedimiento de los derechos humanos universalmente reconocidos, y, de este modo, una mayor limitación de las facultades de injerencia estatal, por un lado, y un aumento de las facultades de intervención del imputado durante el procedimiento, por el otro;

c) el florecimiento de soluciones no tradicionales para el caso penal, que eviten la imposición de la pena estatal tal como fuera clásicamente concebida, incorporando para ello activamente a la víclima del delito -hislóricamente indiferente, tanto para el sistema inquisitivo, como para los modelos mixlos-, y la adopción de sistemas de racionalización de la seleclividad del sistema penal en procura de una aplicación más justa e igualitaria, pero también más eficiente, del ius punendi estatal.

II

La somera descripción de los distintos movimientos reformistas que fueron modelando el procedimiento penal europeo-continental hasta nuestros días debería bastar para comprender cabalmente el increible nivel de atraso material, cultural y político que presentan, en contraste, los sistemas de enjuiciamiento penal de América Latina. 
Los fundamentos históricos de este atraso son ya ampliamente conocidos: la América colonial receptó el sistema penal inquisitivo de la Corona española, y, junto con él, el modelo de organización judicial inherente al absolutismo, es decir, organización centralizada y burocrálica de los órganos de decisión, jerarquicamente estructurados, de modo tal que quedara asegurado el control interno de la aclividad de los funcionarios que impartian justicia en nombre del monarca, mediante la devolución de la jurisdicción al órgano superior, que la había delegado (herencia directa de ello es el llamado "recurso de consulta", en donde un tribunal superior conoce el caso resuelto por uno inferior sin que haya mediado un recurso de parte de alguno de los interesados). La legislación penal colonial, entonces, no fue otra cosa que las Partidas de Alfonso el Sabio, incorporadas a través de las Recopilaciones de Leyes de Indias, y extendidas a lo largo y a lo ancho del conlinente".

Pero así como la recepción del derecho inquisitivo español en Latinoamerica resulta fácilmente explicable, no sucede lo mismo con su perdurabilidad en el tiempo, que coloca a la enorme mayoría de los países de la región, estando en las puertas del s. XIX. Paradójicamente, los movimientos independentistas decimónicos en el continente, herederos culturales y políticos de la ilustración europea, introdujeron en las Constituciones políticas nacionales los principios políticos republicanos y las reglas de garantía en favor de los ciudadanos (así, por ejemplo, la Constitución salvadoreña de 1841 , que, entre olros principios, consagraba el de juicio previo en su Art. $76,1^{\circ}$ parte), y, de este modo, persiguieron claramente romper con la tradición inquisitiva colonial. Sus aspiraciones, sin embargo, fueron burladas por el desarrollo legislativo posterior.

La historia de la legislación procesal penal para el Estado federal en la Argentina es un ejemplo arquetípico de lo que acabo de decir: a pesar del expreso mandato del constituyente argentino al legislador de abandonar la legislación colonial y de implementar el juicio por jurados (por definición, oral, público y contradiclorio) para todos los casos penales, éste adopló, en 1889 , un proyecto de legislación procesal basado en la inquisitoria Compilación de 1879 española, que España había abandonado en 1882 (es decir, siete años antes de su recepción por el legislador argentino) al dictarse la Ley de Enjuiciamiento Criminal, la cual consagraba los principios de oralidad y publicidad del juicio, inmediación, libre valoración de la prueba, etc".

Argentina entró así al s. XX con un reglamento procesal para el Estado federal que prescribía un procedimiento escrito, por acumulación de actas, secreto, con confusión de las funciones instructoria y decisoria para varios casos, burocrático y con un imputado prácticamente carente de facultades sustanciales de intervención durante el procedimiento. Recién en 1992 - hace escasos cuatro años- el Estado nacional se dictó un nuevo código procesal penal; el legislador argentino, sin embargo, repitió en esta ocasión la misma irresponsabilidad histórica que había cometido 100 años atrás, y adoptó como nuevo CPP una copia literal del Código de la 
provincia argentina de Córdoba de 1939, el cual, a su vez, reconocía como fuente al CPP italiano de 1913 —on algunas de las reformas a él introducidas en 1930- y constituía un claro ejemplo de una ley procesal anclada en el modelo mixto del s. XIX.

Precisamente por ello, y debido a los problemas inherentes a dicho modelo descritos al comienzo de ese trabajo, el CPP de Córdoba que sirviera de modelo al legislador nacional estaba siendo abandonado por los cordobeses, quienes finalmente sancionaron para sí un nuevo CPP, que reconoce sus bases en el CPP Modelo para Iberoamérica y en las distintas transformaciones producidas en Europa continental durante este siglo en el ámbito del procedimiento procesal que nacía, igual que su antecesor, "viejo y caduco"'t".

Así las cosas, se puede afirmar que, en la actualidad, América Latina se encuentra rezagada entre 150 y 300 años, según el grado de avance del país que se trate, en lo que al sistema de enjuiciamiento y administración de justicia penal se refiere. Esta perspectiva histórica es completamente soslayada por la argumentación conservadora que pretende rechazar cualquier intento de reforma del statu quo, echando mano, por ejemplo, a intentos chauvinistas de defensa del sistema vigente como producto de una determinada "tradición nacional", frente a intentos "extranjerizantes" de reforma. La hipocresía de este discurso, que abre generosamente las fronteras nacionales al martillo y la hoguera de la inquisición, dándoles carla de ciudadanía, y se las cierra a los ideales libertarios y humanistas de la ilustración, so pretexlo de su "extranjería", me parece autoevidente. No fueron las culturas precolombinas las que modelaron los sistemas penales latinoamericanos, sino las tradiciones culturales y políticas del conquistador.

\section{III}

La década de los 90' vio surgir en el continente, sin embargo, un ímpetu reformista, asimilable a aquél que forjara las bases políticas de las repúblicas latinoamericanas durante el s. XIX. Los resultados de ese proceso, de un vigor inicial sorprendente, son todavía imprecisos, aunque creo que se puede afimar con certeza que la idea de la necesidad de abandonar la tradición procesal inquisitiva se encuentra ya firmemente instalada en el continente. Hoy encontramos países latinoamericanos que pretenden dejar atrás por vez primera la herencia colonial, o que ya la han abandonado, como el caso de El Salvador con sus proyectos de CPP, CP y Ley de Ejecución Penitenciaria, Guatemala, con un nuevo CPP en funcionamiento desde hace ya algún tiempo o Chile con un proyecto de reforma en pleno trámite parlamentario; en otros casos, como el de Costa Rica, o el de varias provincias de la Argentina, se trata de abandonar la rigidez del sistema mixto en pos de un procedimiento penal ajustado a los tiempos que corren. 
¿Por qué, súbilamente, este espíritu reformista? ¿Por qué, a su vez, la resistencia encarnizada que él encuentra muchas veces en distintos sectores, aun con la clara conciencia de que el modelo que se pretende preservar está completamente agotado? Las respuestas posibles son varias. Me limitaré, en lo que queda de mi exposición, a señalar un punto central de la discusión sobre la reforma procesal penal latinoamericana: el de la capacidad de respuesta del sistema penal frenle al fenómeno deliclivo.

Una crítica frecuente a los intentos de reforma se refiere a la crisis de eficiencia que un modelo "excesivamente garantista" - aunque con ello, paradójicamente, se haga alusión a un sistema de enjuiciamiento mínimamente respetuoso de las garantías individuales- podría causarle al sistema penal. Se teme, por ejemplo, que una regulación de la prisión provisional que establezca claramente su carácter excepcional -único, por otro lado, respeluoso del Estado de derecho-, conlleve la imposibilidad de conducir adecuadamente un procedimiento penal; lo mismo vale, por ejemplo, para todas aquellas iniciativas legislativas que pretendan establecer límites claros y regulaciones específicas a las facultades de injerencia estatal en la esfera de derechos fundamentales de los ciudadanos o, incluso, para cuando se pretende tornar efectiva la garantía de defensa de juicio, asegurando, por ejemplo, la defensa técnica del imputado durante el procedimiento.

Si el punto de partida del crílico es el sistema vigente al momento de la crílica, es decir, si el modelo de quien formula la crítica tiene en la cabeza cuando expresa su temor hacia la eventual pérdida de eficiencia es el sistema inquisitivo tradicional, entonces la crílica es, en sí, correcta. La formulación de la prisión provisional como regla general, por ejemplo, es una caraclerística intrínseca del procedimiento escrilo: ya que, casi por definición, eslos procesos duran años y años, el mejor modo de mantener al imputado sujeto al trámite del caso es, precisamente, mantenerlo privado de libertad durante todo el desarrollo del proceso. La libertad del imputado es, en definitiva, la "variable de ajuste" del sistema escrito de enjuciamiento necesila la prisión provisional para todos los casos, del mismo modo que el inquisidor necesilaba el cuerpo del imputado para poder aplicarle la tortura.

Una crítica semejante sería, sin embargo, no sólo metodológicamente falsa, sino también completamente errada en cuanto a la veracidad de su premisa básica: "garantías" no es, en ningún caso, sinónimo de "impunidad", de lo que da cuenta toda la legislación vigente en los países civilizados de la comunidad internacional. Pero además de ello, y vuelvo a la falacia metodológica a la que hacía referencia recién, de lo que se trata no es de introducir ésle o aquél "parche" en el modelo inquisitivo, ya sea "puro" o reformado, sino de una completa ruplura con él, con el fin de lograr no sólo un sistema que resguarde las garantías del imputado - y de los ciudadanos, en general-, sino también un sistema apto para hacer frente a los casos de criminalidad más grave y compleja, para los cuales los sistemas penales latinoamericanos no tienen hoy otra solución que la más absoluta impunidad. 
Tal vez un ejemplo de mi país pueda reflejar más claramente lo que acabo de expresar. Según informes confiables de varias organizaciones no gubernamentales, las industrias que rodean a la ciudad de Buenos Aires son altamente contaminantes e incumplen con las reglas mínimas de control de polución establecidas por la regulación administrativa. La contaminación indiscriminada que producen causa daños permanentes o de muy difícil recuperación al medio ambiente, y pone en grave peligro la vida y salud de los habitantes de las zonas densamente pobladas en las que estas industrias están radicadas, habiéndose ya constatado, incluso, lesiones concrelas.

Sin embargo, según estadísticas recientes de la Dirección de Política Criminal del Ministerio de Justicia de la Nación ", durante el año 1992 apenas se iniciaron 59 investigaciones penales por estos hechos (punibles según las normas del Código Penal Pertinentes y la Ley de Residuos Peligrosos), de las cuales un 38\% concluyó con sobreseimiento o con el archivo del caso, un 19\% fue derivada a otro tribunal por incompetencia, un $\mathbf{4 0 \%}$ se encontraba un año después de su iniciación aún en trámite y sólo un $4 \%$ estaba constituido por casos enviados a juicio. Otro dato relevante es que del total, en un $\mathbf{8 1 \%}$ se trataba de casos sin procesados. En conversaciones con los jueces competentes para la investigación de este tipo de delitos, ellos admitieron la imposibilidad fáctica de tratar adecuadamente estos casos, señalando, entre otros motivos, la gran complejidad de las pruebas técnicas o pericias que se deben realizar para una adecuada investigación.

En verdad, el problema trasciende largamente esta explicación formulada por nuestros jueces, un tanto banal, de las dificultades del sistema penal argentino aunque el ejemplo vale sin duda para toda la región- para encontrar una respuesta adecuada a delitos de esta índole: los sistemas latinoamericanos son completamente incapaces de responder frente a formas complejas de criminalidad, no sólo por la ausencia o inadecuada administración de los recursos materiales existentes, sino, fundamentalmente, por la estructura obsoleta de administración de justicia heredada de la colonia, que obliga a los funcionarios de la persecución penal a perseguir del mismo modo, y con la misma intensidad, un pequeño delito contra la propiedad, un homicidio múlliple o una defraudación fiscal millonaria.

Y, para colmo, ordena para ello un método de investigación penal lento, burocrático y, en la mayoría de los casos, casi interminable. El resultado de sólo puede ser el que hoy todos conocemos bien: los grandes delitos económicos, los delitos ecológicos, los homicidios realizados desde estructuras de poder o con su apoyo, es decir, todos los delitos de mayor impacto social, los que afectan más sensiblemente la propiedad, la vida o la salud de los ciudadanos, permanecen impunes. Impunidad no es sinónimo de garantías; impunidad es sinónimo de inquisición.

Es, por lo tanto, tarea de la reforma procesal latinoamericana el diseño de un modelo de enjuiciamiento penal apto para dar una respuesta adecuada a las formas complejas y organizadas de criminalidad. EI Pr. de CPP de El Salvador va, en este 
sentido, por la senda correcta, mediante la formulación de reglas tendentes a la desformalización y agilización de la etapa de investigación preliminar al juicio, siguiendo una estructura imaginativa, $y$, hasła donde yo sé, única en el continente, al contener una audiencia inicial, posterior a la investigación fiscal, y una audiencia preliminar al juicio, con la que concluye la elapa de instrucción formal, y, por otro lado, mediante la adopción de criterios de oportunidad para el ejercicio de la acción penal, permitiendo canalizar y corregir la selectividad espontánea del sistema penal y concentrar esfuerzos y tiempo material para los casos más graves, y de salidas alternativas del caso, como la suspensión del procedimiento a prueba o la conciliación entre autor y víctima, que no sólo prohíjan una solución más humana para el conflicto, sino que también redundan en una sustancial descarga de trabajo para el sistema penal.

\section{$\mathbf{v}$}

Los desafíos, como se ve, son múltiples, y demandan un esfuerzo y una imaginación enormes. Se trata de revertir un sistema penal violatorio de los principios básicos inherentes a la dignidad humana, pero, además de ello, absolutamente ineficiente para la adecuada persecución de los delitos más graves, y que, para tranquilizar su conciencia, se limita a pulverizar los derechos de aquellos que normalmente, por la escasa envergadura del hecho que han cometido- tienen la mala suerte de caer en sus redes. Se trata, entonces, de revertir el atraso de siglos en nuestros sistemas de enjuiciamiento penal, y de ingresar al s. XXI ya definitivamente desprovistos del andrajoso ropaje colonial con el que nos hemos vestido hasta hoy.

\section{Notas}

1. Ponencia pronunciada en la Conferencia "Juslicia penal y Estado democrático", aclividad del proyecto "Participación ciudadana en la reforma del sistema judicial", ejecutado por la Fundación de Esludios para la Aplicación del Derecho FESPAD, a través del Centro de Estudios Penales de El Salvador -CEPES.

2. Derecho Procesal Penal, Córdoba, 1943, p.7.

3. Sobre esta evolución histórica, aquí referida sintéticamente, ver Maier, Derecho Procesal Penal, Buenos Aires, 1996, ps. 288.

4. Ferrajoli, Luigi, Derecho y Razón, Madrid, 1995, p.566.

5. p.566.

6. Así, TEDH, casos "Piersack" (1982) y "De Cubber" (1984).

7. Sobre lo recién expuesto, ver, entre otros, Hassemmer, Winfried, Fundamentos de Derecho Penal, Barcelona, 1984; Zipf, Heinz. Introducción a la política criminal, Madrid, 1979; Roxin, Claus, Strafrecht. Allgemeiner Teil, München, 1994, ps. 63 y ss.

8. Cf, Maier, Julio, Democracla y administración de justicia penal en lberoamérica, cn “Jueces para la Democracia", Ns. 16-17, Madrid, 1992, ps. 148 y ss. 
9. Cr Maier, Derecho Procesal Penal, ps. 405 y ss.

10. Crítica al CPP nacional de 1989 formulada por Alfredo Vélez Mariconde, Derecho Procesal Penal, Bs.As., 1969, T.I, p. 197.

11. Hacia un plan nacional de política criminal, Ministerio de Justicia de la Nación, Bs.As., 1996, ps. 136 y ss. 